\title{
The assessment of herbicides application with biostimulants and adjuvants in carrot (Daucus carota L.)
}

\author{
Ocena stosowania herbicydów z biostymulatorami i adiuwantami \\ w uprawie marchwi (Daucus carota L.)
}

\author{
Joanna Golian, Zbigniew Anyszka, Małgorzata Kohut
}

\begin{abstract}
Summary
The studies were conducted in 2010-2011 at the Research Institute of Horticulture in Skierniewice. The aim of the research was to determine the impact of separate and combined application of biostimulants Asahi SL and AlfaMax, adjuvants Olbras 88 EC and Protector on efficacy of metribuzin and linuron and the growth and yield of carrot. Herbicides were used with split-application method. First treatment with metribuzin and linuron was applied at 1 leaf stage of carrot, the second treatment of linuron was performed 10-14 days after the first one, and metribuzin was applied at 2-3 leaves stage of carrot. Asahi SL, AlfaMax, Olbras 88 EC and Protector were applied in mixture with herbicides or separate -1 day before or 1 day after herbicide treatment. The weed control, number and biomass of weeds, phytotoxicity of tested herbicides and the yield of carrot roots were determined during the experiments. Better weed control was achieved with metribuzin than linuron and the addition of biostimulants and adjuvants did not affect its effectiveness. The addition of adjuvants increased the efficacy of linuron. Applied substances did not increase the phytotoxicity of herbicides to carrot plants. The highest yield was obtained by using a mixture of metribuzin with Asahi SL and Protector at 1 day before metribuzin application.
\end{abstract}

Key words: carrot; weed; herbicide; biostimulant; adjuvant

\section{Streszczenie}

W latach 2010-2011, w Instytucie Ogrodnictwa prowadzono badania nad określeniem wpływu rozdzielnego i łącznego stosowania biostymulatorów Asahi SL i AlfaMax oraz adiuwantów Olbras 88 EC i Protector na skuteczność działania metrybuzyny i linuronu oraz wzrost i plonowanie marchwi. Herbicydy stosowano metodą dawek dzielonych. Pierwszy zabieg metrybuzyną i linuronem wykonywano w fazie 1 liścia właściwego marchwi, drugi zabieg linuronem po 10-14 dniach od pierwszego, a metrybuzyną w fazie 2-3 liści marchwi. Asahi SL, AlfaMax oraz Olbras 88 EC i Protector stosowano łącznie z herbicydami lub w zabiegach rozdzielnych - 1 dzień przed lub 1 dzień po zabiegu herbicydem. Przeprowadzano obserwacje stopnia zniszczenia chwastów, określano ich liczbę i świeżą masę, stopień fitotoksyczności badanych środków dla marchwi i wysokość plonów. Stwierdzono lepsze działanie chwastobójcze metrybuzyny stosowanej metodą dawek dzielonych niż linuronu, a biostymulatory i adiuwanty nie wpływały na jej skuteczność. Dodatek adiuwantów zwiększył skuteczność działania linuronu. Stosowane substancje nie powodowały wzrostu fitotoksyczności badanych herbicydów dla marchwi. Najwyższy plon uzyskano stosując mieszaninę metrybuzyny z Asahi SL oraz Protector na jeden dzień przed zastosowaniem metrybuzyny.

Słowa kluczowe: marchew; chwasty; herbicyd; biostymulator; adiuwant 


\section{Wstęp / Introduction}

Do zwalczania chwastów po wschodach marchwi (Daucus carota L.) zalecane są herbicydy zawierające metrybuzynę i linuron (Bellinder i wsp. 1997; Anyszka i Dobrzański 2003; Anyszka 2007). Substancje te moga być stosowane metodą dawek dzielonych lub mikrodawek (Anyszka i Dobrzański 1998; Anyszka i wsp. 2001, 2011). Warunki wzrostu roślin i przebieg procesów fizjologicznych, takich jak kiełkowanie czy tworzenie i rozwój korzeni, można polepszać przez stosowanie biostymulatorów syntetycznych lub naturalnych, często opartych na wyciagach z alg morskich (Szweykowska 1997; Dobrzański i wsp. 2008a, b; Dobromilska i wsp. 2009; Gawrońska i Przybysz 2011; Matysiak i wsp. 2011). Stosowanie biostymulatorów jest szczególnie polecane w warunkach stresowych, np. w czasie długotrwałej suszy, braku składników odżywczych w glebie, w warunkach wysokiego zasolenia gleby (Matysiak i Adamczewski 2009), a także przy stosowaniu środków ochrony roślin.

Biostymulatory pochodzenia naturalnego zawierają wyciagi i ekstrakty roślinne oraz wyciągi z alg morskich, m.in. gatunków rodzaju Sargassum, a także Ascophyllum nodosum, Durvillea potatorum, Eclonia maxima, Foccus serratus, Fucus vesiculosus, Laminaria digitata, Laminaria hyperborea (Dobrzański i wsp. 2008a; Gubarewicz i Dobromilska 2010). W ich skład wchodzą także hormony roślinne, enzymy, aminokwasy, białka, mikroelementy. Do tej grupy substancji zalicza się AlfaMax. Biostymulatorem syntetycznym, zawierającym w swoim składzie nitrofenole - pochodne polifenoli jest Asahi SL, zalecany w Polsce, m.in. w roślinach warzywnych. Związki te nie są szkodliwe dla środowiska i konsumentów, występują w komórkach roślin i biorą udział w licznych procesach fizjologicznych i biochemicznych (Czeczko i Mikos-Bielak 2004; Maciejewski i wsp. 2007; Gawrońska i wsp. 2008; Matysiak i wsp. 2011). Biostymulatory obniżają stężenia auksyn w roślinie, zmniejszając tym samym podatność na czynniki stresowe (Gawrońska i Przybysz 2011; Matysiak i wsp. 2011).

Do zwiększania skuteczności działania niektórych herbicydów stosowanych nalistnie, zaleca się dodatek adiuwantów do cieczy użytkowej (Dobrzański i wsp. 1995; Praczyk i Adamczewski 1996; Woźnica i Adamczewski 2005). Zaliczamy do nich, m.in. Olbras 88 EC i Protector. Terminy stosowania $\mathrm{w}$ marchwi nalistnie działających herbicydów i biostymulatorów często są zbieżne, dlatego też uzasadnione jest ich łączne stosowanie.

Celem badań było określenie wpływu rozdzielnego i łącznego stosowania biostymulatorów Asahi SL i AlfaMax oraz adiuwantów Olbras 88 EC i Protector na skuteczność działania metrybuzyny i linuronu, plonowanie marchwi oraz łagodzenie stresu związanego $\mathrm{z}$ ich stosowaniem.

\section{Materiały i metody / Materials and methods}

Badania przeprowadzono w latach 2010-2011 na polu doświadczalnym Instytutu Ogrodnictwa. Wykonywano je na glebie płowej, wytworzonej z utworów piaskowych na glinie zwałowej (1,3-1,5\% substancji organicznych, $\mathrm{pH}$
6,5). Doświadczenia zakładano metodą losowanych bloków, w układzie jednoczynnikowym, w 4 powtórzeniach. Wielkość poletek wynosiła $9 \mathrm{~m}^{2}$. Marchew, odmiany Nerac $F_{1}$, wysiewano w rzędy w rozstawie $40 \mathrm{~cm}$, w ilości 51-53 sztuk nasion na 1 metr bieżący rzędu, w dniu 28 kwietnia, w obu latach badań. Badaniami objęto herbicydy zawierające metrybuzynę (Sencor Liquid 600 SC) i linuron (Linurex $500 \mathrm{SC}$ ), które stosowano wcześnie po wschodach marchwi, metodą dawek dzielonych. Pierwszy zabieg tymi środkami wykonywano w fazie 1 liścia właściwego marchwi, natomiast w drugim zabiegu linuron stosowano po 10-14 dniach od pierwszego opryskiwania, a metrybuzynę $\mathrm{w}$ fazie 2-3 liści marchwi. W poszczególnych zabiegach metrybuzynę stosowano w dawce $150 \mathrm{~g} / \mathrm{ha}$, a linuron - $250 \mathrm{~g} / \mathrm{ha}$. Biostymulatory Asahi SL (para-nitrofenolan sodu $-0,3 \%+$ orto-nitrofenolan sodu $-0,2 \%+5$-nitrogwajakolan sodu $-0,1 \%$ ) i AlfaMax (wyciagi z alg morskich oraz L-aminokwasy, hormony, auksyny, gibereliny, cytokininy) oraz adiuwanty Olbras 88 EC (88\% kwasy thuszczowe porafinacyjne oleju rzepakowego) i Protector (Di-1-P-menten - związek $\mathrm{z}$ grupy terpenowych polimerów, wytwarzany $\mathrm{z}$ żywicy sosny amerykańskiej) stosowano łącznie z herbicydami lub w zabiegach rozdzielnych -1 dzień przed lub 1 dzień po opryskiwaniu herbicydem. Asahi SL stosowano w każdym zabiegu w dawce 0,5 1/ha, AlfaMax - 1 1/ha, Olbras 88 EC - 1,5 1/ha, a Protector - 0,4 1/ha. Zabiegi wykonywano przy użyciu kołowego opryskiwacza poletkowego na sprężone powietrze, zaopatrzonego $\mathrm{w}$ rozpylacze płaskostrumieniowe Tee-Jet 110-02 VS, zużywając 2201 wody na ha, przy ciśnieniu roboczym $0,2 \mathrm{MPa}$. Wyniki zastosowania herbicydów $\mathrm{z}$ biostymulatorami i adiuwantami porównywano do działania samych herbicydów i do kontroli, w której nie wykonywano żadnych zabiegów.

Stopień zniszczenia chwastów oceniano szacunkowo w \% po 20-34 dniach, a liczbę i masę chwastów określano metodą ramkowo-wagową po 20-36 dniach od pierwszego zabiegu herbicydami. Fitotoksyczność badanych środków dla marchwi określano w \% (0 - brak uszkodzeń, 100 rośliny zniszczone) po 10-14 i 22-35 dniach od ostatniego zabiegu herbicydowego. Liczbę roślin marchwi w rzędzie określono po 49-63 dniach od siewu i w czasie zbioru marchwi. Zbiór korzeni marchwi przeprowadzono w fazie dojrzałości zbiorczej, po 112-161 dniach wegetacji. Określono plon ogólny, handlowy oraz masę naci. Wyniki plonów korzeni i naci poddano analizie statystycznej w oparciu o program analizy wariancji dla doświadczenia jednoczynnikowego, wykorzystujący test Newmana-Keulsa do oceny różnic między średnimi, przy poziomie istotności 5\%.

\section{Wyniki i dyskusja / Results and discussion}

W doświadczeniach, w największym nasileniu występowały chwasty dwuliścienne takie, jak: pokrzywa żegawka (Urtica urens L.), komosa biała (Chenopodium album L.), tasznik pospolity (Capsella bursa-pastoris L.), jasnota różowa (Lamium amplexicaule L.), starzec zwyczajny (Senecio vulgaris L.), żółtlica drobnokwiatowa (Galinsoga parviflora Cav.), a z gatunków jednoliściennych chwastnica jednostronna (Echinochloa crus-galli L.). 


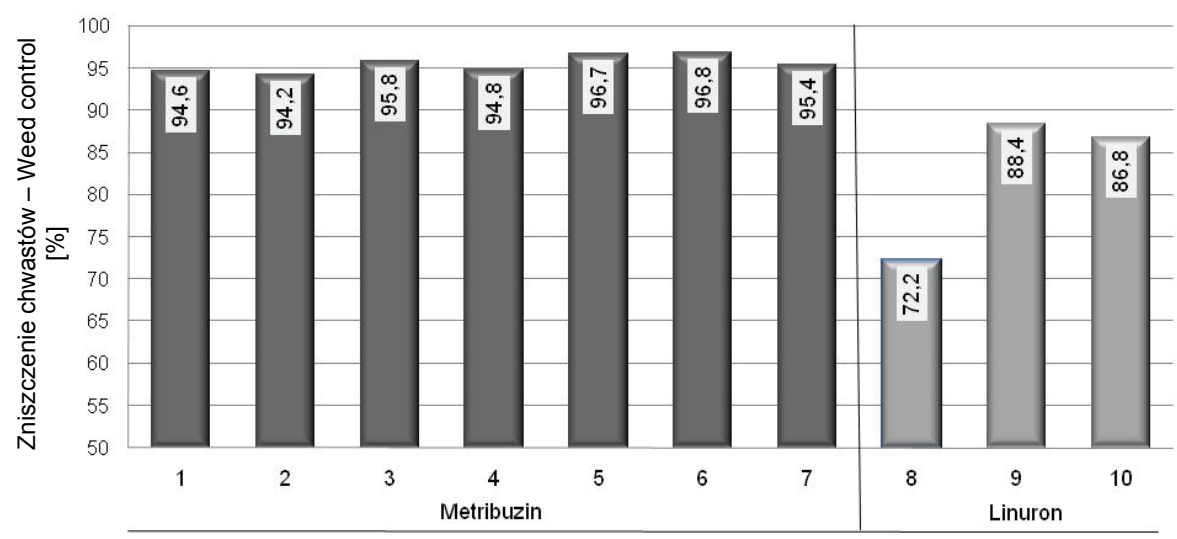

1 - Metribuzin; 2 - Metribuzin + Asahi SL (mieszanina - mixture); 3 - Metribuzin + Asahi SL (1 dzień po - 1 day after); 4 - Metribuzin + AlfaMax (mieszanina mixture); 5 - AlfaMax (1 dzień przed - 1 day before) + metribuzin; 6 - Metribuzin + Protector (mieszanina - mixture); 7 - Protector (1 dzień przed - 1 day before) + metribuzin; 8 - Linuron; 9 - Linuron + Olbras 88 EC (mieszanina - mixture); 10 - Protector (1 dzień przed - 1 day before) + linuron + Olbras 88 EC (mieszanina - mixture)

Dawki herbicydów i innych środków na ha - Herbicides and other product doses per ha: metribuzin $-2 \times 150 \mathrm{~g}$; linuron $-2 \times 250 \mathrm{~g}$; Asahi SL - $2 \times 0,5 \mathrm{l}$; AlfaMax - $2 \times 1$ l; Olbras $88 \mathrm{EC}-2 \times 1,5 \mathrm{l}$; Protector $-2 \times 0,4 \mathrm{I}$

Rys. 1. Stopień zniszczenia chwastów ogółem po zastosowaniu herbicydów metodą dawek dzielonych w uprawie marchwi (2010-2011)

Fig. 1. Total weed species control by herbicides used with split application method in carrot (2010-2011)

Tabela 1. Zniszczenie gatunków chwastów w marchwi, w zależności od stosowanych środków

Table 1. Weed species control in carrot, depending on the usage of compounds

Średnie z lat - Means for 2010-2011, Skierniewice

\begin{tabular}{|c|c|c|c|c|c|c|c|c|c|}
\hline \multirow{2}{*}{$\begin{array}{c}\text { Badane środki, dawki } \\
\text { Tested products, doses } \\
{[1 / \text { ha }]}\end{array}$} & \multirow{2}{*}{$\begin{array}{c}\text { Termin } \\
\text { zabiegu } \\
\text { Term of } \\
\text { application }\end{array}$} & \multicolumn{8}{|c|}{ Stopień zniszczenia gatunków chwastów - Weed species control [\%] } \\
\hline & & 需 & 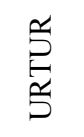 & 离 & 商 & 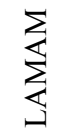 & 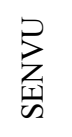 & 峁 & 导 \\
\hline Metribuzin $-2 \times 0,25$ & $\mathrm{~T}_{2}, \mathrm{~T}_{5}$ & 94,6 & 96,3 & 94,4 & 98,8 & 100 & 74,4 & 100 & 42,7 \\
\hline $\begin{array}{l}\text { Metribuzin }-2 \times 0,25 \\
+ \text { Asahi SL }-2 \times 0,5\end{array}$ & $\begin{array}{r}\mathrm{T}_{2}, \mathrm{~T}_{5} \\
+\mathrm{T}_{2}, \mathrm{~T}_{5} \\
\end{array}$ & 94,2 & 97,3 & 90,2 & 98,8 & 100 & 79,8 & 100 & 63,8 \\
\hline $\begin{array}{l}\text { Metribuzin }-2 \times 0,25 \\
+ \text { Asahi SL }-2 \times 0,5\end{array}$ & $\begin{array}{r}\mathrm{T}_{2}, \mathrm{~T}_{5} \\
+\mathrm{T}_{3}, \mathrm{~T}_{6}\end{array}$ & 95,8 & 97,8 & 93,4 & 99,4 & 100 & 80,3 & 100 & 62,3 \\
\hline $\begin{array}{l}\text { Metribuzin }-2 \times 0,25 \\
+ \text { AlfaMax }-2 \times 1\end{array}$ & $\begin{array}{r}\mathrm{T}_{2}, \mathrm{~T}_{5} \\
+\mathrm{T}_{2}, \mathrm{~T}_{5}\end{array}$ & 94,8 & 98,8 & 96,2 & 99,7 & 100 & 89,8 & 100 & 53,8 \\
\hline $\begin{array}{l}\text { AlfaMax }-2 \times 1 \\
+ \text { Metribuzin }-2 \times 0,25\end{array}$ & $\begin{array}{r}\mathrm{T}_{1}, \mathrm{~T}_{4} \\
+\mathrm{T}_{2}, \mathrm{~T}_{5}\end{array}$ & 96,7 & 97,7 & 94,9 & 98,9 & 99,8 & 87,4 & 100 & 44,4 \\
\hline $\begin{array}{l}\text { Metribuzin }-2 \times 0,25 \\
+ \text { Protector }-2 \times 0,4\end{array}$ & $\begin{array}{r}\mathrm{T}_{2}, \mathrm{~T}_{5} \\
+\mathrm{T}_{2}, \mathrm{~T}_{5} \\
\end{array}$ & 96,8 & 98,2 & 97,9 & 99,3 & 100 & 88,4 & 98,8 & 73,8 \\
\hline $\begin{array}{l}\text { Protector }-2 \times 0,4 \\
+ \text { Metribuzin }-2 \times 0,25\end{array}$ & $\begin{array}{r}\mathrm{T}_{1}, \mathrm{~T}_{4} \\
+\mathrm{T}_{2}, \mathrm{~T}_{5} \\
\end{array}$ & 95,4 & 96,3 & 95,8 & 98,9 & 100 & 86,9 & 96,9 & 52,5 \\
\hline Linuron $-2 \times 0,5$ & $\mathrm{~T}_{2}, \mathrm{~T}_{8}$ & 72,2 & 94,4 & 72,8 & 99,3 & 74,3 & 34,8 & 95,7 & 33,2 \\
\hline $\begin{array}{l}\text { Linuron }-2 \times 0,5 \\
+ \text { Olbras } 88 \mathrm{EC}-2 \times 1,5\end{array}$ & $\begin{array}{r}\mathrm{T}_{2}, \mathrm{~T}_{8} \\
+\mathrm{T}_{2}, \mathrm{~T}_{8} \\
\end{array}$ & 88,4 & 99,8 & 100 & 99,0 & 75,8 & 45,7 & 71,9 & 64,9 \\
\hline $\begin{array}{l}\text { Protector }-2 \times 0,4 \\
+ \text { Linuron }-2 \times 0,5 \\
+ \text { Olbras } 88 \mathrm{EC}-2 \times 1,5\end{array}$ & $\begin{aligned} & \mathrm{T}_{1}, \mathrm{~T}_{7} \\
+ & \mathrm{T}_{2}, \mathrm{~T}_{8} \\
+ & \mathrm{T}_{2}, \mathrm{~T}_{8}\end{aligned}$ & 86,8 & 100 & 99,9 & 98,5 & 81,0 & 42,9 & 84,8 & 63,3 \\
\hline \multicolumn{2}{|c|}{$\begin{array}{l}\text { Kontrola - pokrycie gleby przez chwasty } \\
\text { Check - ground cover by weeds [\%] }\end{array}$} & 74,2 & 7,8 & 16,0 & 19,1 & 5,7 & 5,3 & 4,5 & 2,0 \\
\hline
\end{tabular}

$\mathrm{T}_{1}-24$ godziny przed herbicydem (1 liść marchwi); $\mathrm{T}_{2}$ - faza 1 liścia marchwi; $\mathrm{T}_{3}-24$ godziny po herbicydzie (1 liść marchwi); $\mathrm{T}_{4}-24$ godzin przed herbicydem (2-3 liście marchwi); $\mathrm{T}_{5}-$ faza $2-3$ liści marchwi; $\mathrm{T}_{6}-24$ godziny po herbicydzie (2-3 liście marchwi); $\mathrm{T}_{7}-24$ godziny przed herbicydem (10-14 dni po $\left.\mathrm{T}_{2}\right) ; \mathrm{T}_{8}-10-14$ dni po $\mathrm{T}_{2}$

$\mathrm{T}_{1}-24$ hours before herbicide (1 leaf of carrot); $\mathrm{T}_{2}-1$ leaf of carrot; $\mathrm{T}_{3}-24$ hours after herbicide (1 leaf of carrot); $\mathrm{T}_{4}-24$ hours before herbicide (2-3 leafs of carrot); $\mathrm{T}_{5}-2-3$ leafs of carrot; $\mathrm{T}_{6}-24$ hours after herbicide (2-3 leafs of carrot); $\mathrm{T}_{7}-24$ hours before herbicide $\left(10-14\right.$ days after $\left.\mathrm{T}_{2}\right)$; $\mathrm{T}_{8}-10-14$ after $\mathrm{T}_{2}$

URTUR - Urtica urens, CHEAL - Chenopodium album, CAPBP - Capsella bursa-pastoris, LAMAM - Lamium amplexicaule, SENVU - Senecio vulgaris, GASPA - Galinsoga parviflora, ECHCG - Echinochloa crus-galli 


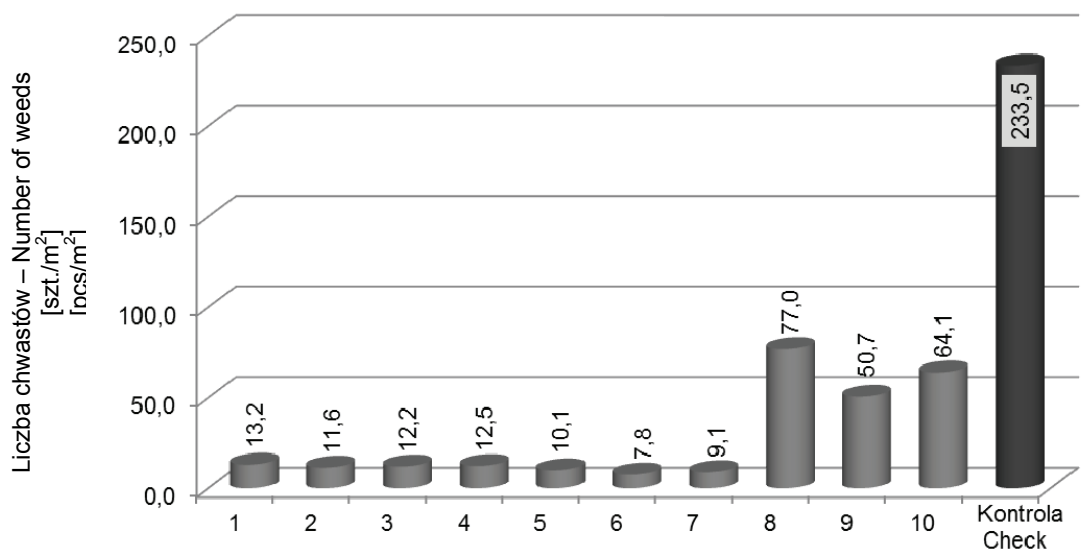

1 - Metribuzin; 2 - Metribuzin + Asahi SL (mieszanina - mixture); 3 - Metribuzin + Asahi SL (1 dzień po - 1 day after); 4 - Metribuzin + AlfaMax (mieszanina - mixture); 5 - AlfaMax (1 dzień przed - 1 day before) + metribuzin; 6 - Metribuzin + Protector (mieszanina - mixture); 7 - Protector (1 dzień przed - 1 day before) + metribuzin; 8 - Linuron; 9 - Linuron + Olbras 88 EC (mieszanina - mixture); 10 - Protector (1 dzień przed - 1 day before) + linuron + Olbras 88 EC (mieszanina - mixture)

Dawki herbicydów i innych środków na ha - Herbicides and other product doses per ha: metribuzin $-2 \times 150 \mathrm{~g}$; linuron $-2 \times 250 \mathrm{~g}$; Asahi SL $-2 \times 0,5 \mathrm{l}$; AlfaMax $-2 \times 1 \mathrm{I}$; Olbras $88 \mathrm{EC}-2 \times 1,5 \mathrm{l}$; Protector $-2 \times 0,4 \mathrm{I}$

Rys. 2. Liczba chwastów ogółem w uprawie marchwi (średnie $\mathrm{z}$ lat 2010-2011)

Fig. 2. The total number of weeds in carrot (means for 2010-2011)

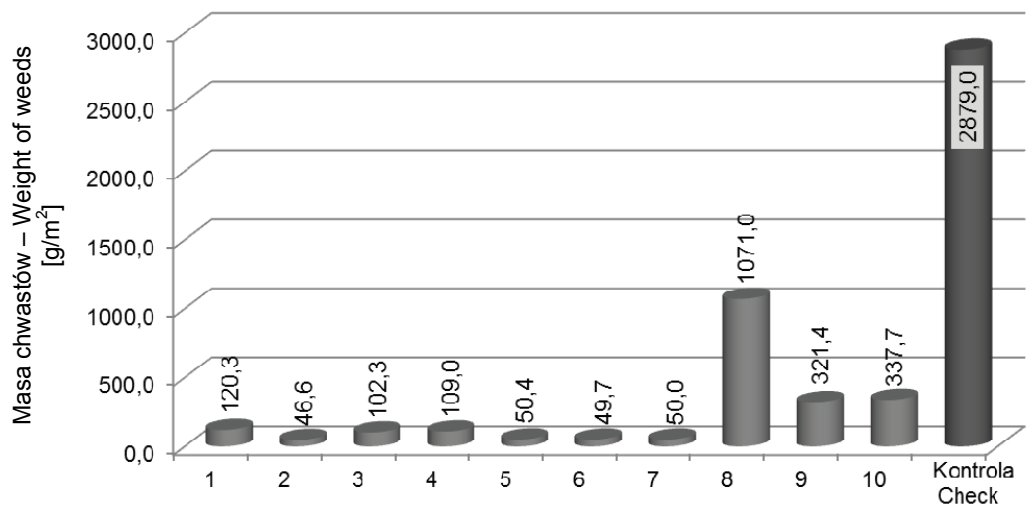

1 - Metribuzin; 2 - Metribuzin + Asahi SL (mieszanina - mixture); 3 - Metribuzin + Asahi SL (1 dzień po - 1 day after); 4 - Metribuzin + AlfaMax (mieszanina - mixture); 5 - AlfaMax (1 dzień przed - 1 day before) + metribuzin; 6 - Metribuzin + Protector (mieszanina - mixture); 7 - Protector (1 dzień przed - 1 day before) + metribuzin; 8 - Linuron; 9 - Linuron + Olbras 88 EC (mieszanina - mixture); 10 - Protector (1 dzień przed - 1 day before) + linuron + Olbras 88 EC (mieszanina - mixture)

Dawki herbicydów i innych środków na ha - Herbicides and other product doses per ha: metribuzin $-2 \times 150 \mathrm{~g}$; linuron $-2 \times 250 \mathrm{~g}$; Asahi SL $-2 \times 0,5 \mathrm{l}$; AlfaMax - $2 \times 1 \mathrm{I}$; Olbras $88 \mathrm{EC}-2 \times 1,5 \mathrm{l}$; Protector $-2 \times 0,4 \mathrm{I}$

Rys. 3. Masa chwastów ogółem w uprawie marchwi (średnie z lat 2010-2011)

Fig. 3. Weight of weeds in carrot (means for 2010-2011)

W mniejszym nasileniu pojawiały się: tobołki polne (Thlaspi arvense L.), gwiazdnica pospolita (Stellaria media L.), iglica pospolita (Erodium cicutarium L.), maruna bezwonna (Matricaria inodora L.) i szarłat szorstki (Amaranthus retroflexus L.). Wyniki badań pokazuja, że metrybuzyna stosowana metodą dawek dzielonych, bez stymulatorów i adiuwantów lepiej niszczyła chwasty $(94,6 \%)$ niż linuron (72,2\%) (tab. 1).

Zastosowanie biostymulatorów i adiuwantów rozdzielnie lub łącznie $\mathrm{z}$ herbicydami, nie wpływało na skuteczność działania metrybuzyny, natomiast stwierdzono zwiększenie stopnia zniszczenia chwastów po użyciu linuronu $\mathrm{z}$ adiuwantem Olbras $88 \mathrm{EC}$ oraz po zastosowaniu adiuwanta Protector jeden dzień przed zabiegiem linuronem (rys. 1). Olbras 88 EC dodany do cieczy użytkowej linuronu zwiększał stopień zniszczenia chwas- tów o 22,4\% w porównaniu do samego linuronu. Adiuwanty dodaje się do zbiornika opryskiwacza w celu zmodyfikowania właściwości biologicznych substancji czynnej bądź zmiany cech fizykochemicznych cieczy użytkowej (Woźnica 2003). W badaniach Dobrzańskiego i wsp. (2008b) wykonywanych w uprawie marchwi, stopień zniszczenia chwastów przez linuron przekraczał 90\%, a użycie Asahi SL w mieszaninie bądź 2-3 dni po zastosowaniu linuronu nie wpływało na skuteczność chwastobójczą tego środka. Biostymulatory i adiuwanty różnie wpływały na stopień zniszczenia gatunków chwastów przez herbicydy. Mieszanina metrybuzyny z biostymulatorem AlfaMax lepiej niszczyła komosę białą niż sama metrybuzyna. Biostymulatory i adiuwanty poprawiały zniszczenie pokrzywy żegawki, starca zwyczajnego i chwastnicy jednostronnej, niezależnie od 
Tabela 2. Fitotoksyczność badanych środków dla marchwi, liczba roślin oraz masa naci i plony korzeni marchwi

Table 2. Phytotoxicity of tested products to carrot, the number of plants and biomass of leaves and yield of carrot roots

Średnie z lat - Means for 2010-2011, Skierniewice

\begin{tabular}{|c|c|c|c|c|c|c|c|}
\hline \multirow{2}{*}{$\begin{array}{c}\text { Badane środki, dawki } \\
\text { Tested products, doses } \\
{[1 / \mathrm{ha}]}\end{array}$} & \multirow{2}{*}{$\begin{array}{c}\text { Termin } \\
\text { zabiegu } \\
\text { Term } \\
\text { of } \\
\text { application }\end{array}$} & \multirow{2}{*}{$\begin{array}{c}\text { Fitotoksyczność }^{1} \\
\text { Phytotoxicity } \\
{[\%]}\end{array}$} & \multicolumn{2}{|c|}{$\begin{array}{c}\text { Obsada marchwi } \\
\text { w szt./1 mb rzędu } \\
\text { Density of carrot plants } \\
\text { per } 1 \mathrm{~m} \text { of row }\end{array}$} & \multirow{2}{*}{$\begin{array}{c}\text { Masa naci } \\
\text { marchwi }^{2} \\
\text { Biomass } \\
\text { of carrot } \\
\text { leaves } \\
{\left[\mathrm{kg} / 100 \mathrm{~m}^{2}\right]}\end{array}$} & \multicolumn{2}{|c|}{$\begin{array}{l}\text { Plony marchwi } \\
\text { Yields of carrot } \\
{\left[\mathrm{kg} / 100 \mathrm{~m}^{2}\right]}\end{array}$} \\
\hline & & & $\begin{array}{l}\text { w czasie } \\
\text { wegetacji } \\
\text { during } \\
\text { vegetation }\end{array}$ & $\begin{array}{l}\text { przed } \\
\text { zbiorem } \\
\text { before } \\
\text { harvest }\end{array}$ & & $\begin{array}{l}\text { ogólny } \\
\text { total }\end{array}$ & $\begin{array}{l}\text { handlowy } \\
\text { marketable }\end{array}$ \\
\hline Metribuzin $-2 \times 0,25$ & $\mathrm{~T}_{2}, \mathrm{~T}_{5}$ & 0,1 & 28,7 & 24,3 & $155,6 \mathrm{ab}$ & $673,7 \mathrm{a}$ & $560,7 \mathrm{a}$ \\
\hline $\begin{array}{l}\text { Metribuzin }-2 \times 0,25 \\
+ \text { Asahi SL }-2 \times 0,5\end{array}$ & $\begin{array}{r}\mathrm{T}_{2}, \mathrm{~T}_{5} \\
+\mathrm{T}_{2}, \mathrm{~T}_{5} \\
\end{array}$ & 0,2 & 30,4 & 26,9 & $164,9 \mathrm{ab}$ & $730,1 \mathrm{a}$ & 625,9 a \\
\hline $\begin{array}{l}\text { Metribuzin }-2 \times 0,25 \\
+ \text { Asahi SL }-2 \times 0,5\end{array}$ & $\begin{array}{r}\mathrm{T}_{2}, \mathrm{~T}_{5} \\
+\mathrm{T}_{3}, \mathrm{~T}_{6}\end{array}$ & 0,3 & 29,1 & 26,8 & $157,0 \mathrm{ab}$ & $712,2 \mathrm{a}$ & 608,6 a \\
\hline $\begin{array}{l}\text { Metribuzin }-2 \times 0,25 \\
+ \text { AlfaMax }-2 \times 1\end{array}$ & $\begin{array}{r}\mathrm{T}_{2}, \mathrm{~T}_{5} \\
+\mathrm{T}_{2}, \mathrm{~T}_{5} \\
\end{array}$ & 0 & 29,4 & 25,3 & $158,1 \mathrm{ab}$ & $655,0 \mathrm{a}$ & 549,8 a \\
\hline $\begin{array}{l}\text { AlfaMax }-2 \times 1 \\
+ \text { Metribuzin }-2 \times 0,25\end{array}$ & $\begin{array}{r}\mathrm{T}_{1}, \mathrm{~T}_{4} \\
+\mathrm{T}_{2}, \mathrm{~T}_{5}\end{array}$ & 0,2 & 28,3 & 24,6 & $151,9 \mathrm{ab}$ & 629,3 a & 523,2 a \\
\hline $\begin{array}{l}\text { Metribuzin }-2 \times 0,25 \\
+ \text { Protector }-2 \times 0,4\end{array}$ & $\begin{array}{r}\mathrm{T}_{2}, \mathrm{~T}_{5} \\
+\mathrm{T}_{2}, \mathrm{~T}_{5} \\
\end{array}$ & 0,5 & 31,3 & 24,8 & $151,7 \mathrm{ab}$ & $678,0 \mathrm{a}$ & 589,4 a \\
\hline $\begin{array}{l}\text { Protector }-2 \times 0,4 \\
+ \text { Metribuzin }-2 \times 0,25\end{array}$ & $\begin{array}{r}\mathrm{T}_{1}, \mathrm{~T}_{4} \\
+\mathrm{T}_{2}, \mathrm{~T}_{5}\end{array}$ & 0,1 & 31,3 & 27,4 & 170,9 a & $726,5 \mathrm{a}$ & $628,3 \mathrm{a}$ \\
\hline Linuron $-2 \times 0,5$ & $\mathrm{~T}_{2}, \mathrm{~T}_{8}$ & 0,1 & 27,8 & 26,3 & $140,3 \mathrm{~b}$ & 639,5 & $549,8 \mathrm{a}$ \\
\hline $\begin{array}{l}\text { Linuron }-2 \times 0,5 \\
+ \text { Olbras } 88 \mathrm{EC}-2 \times 1,5\end{array}$ & $\begin{array}{r}\mathrm{T}_{2}, \mathrm{~T}_{8} \\
+\mathrm{T}_{2}, \mathrm{~T}_{8} \\
\end{array}$ & 0,1 & 29,3 & 25,4 & $156,0 \mathrm{ab}$ & $672,1 \mathrm{a}$ & 570,6 a \\
\hline $\begin{array}{l}\text { Protector }-2 \times 0,4 \\
+ \text { Linuron }-2 \times 0,5 \\
+ \text { Olbras } 88 \text { EC }-2 \times 1,5\end{array}$ & $\begin{aligned} & \mathrm{T}_{1}, \mathrm{~T}_{7} \\
&+ \mathrm{T}_{2}, \mathrm{~T}_{8} \\
&+ \mathrm{T}_{2}, \mathrm{~T}_{8} \\
&\end{aligned}$ & 0,2 & 29,3 & 25,4 & $146,3 \mathrm{ab}$ & 669,9 a & $581,5 \mathrm{a}$ \\
\hline Kontrola - Check & - & 0 & 25,2 & 21,5 & $85,6 \mathrm{c}$ & $374,5 \mathrm{~b}$ & $287,5 \mathrm{~b}$ \\
\hline
\end{tabular}

$\mathrm{T}_{1}-24$ godziny przed herbicydem (1 liść marchwi); $\mathrm{T}_{2}$ - faza 1 liścia marchwi; $\mathrm{T}_{3}-24$ godziny po herbicydzie (1 liść marchwi); $\mathrm{T}_{4}-24$ godziny przed herbicydem (2-3 liście marchwi); $\mathrm{T}_{5}$ - faza $2-3$ liści marchwi; $\mathrm{T}_{6}-24$ godziny po herbicydzie ( $2-3$ liście marchwi); $\mathrm{T}_{7}-24$ godziny przed herbicydem $\left(10-14\right.$ dni po $\left.\mathrm{T}_{2}\right) ; \mathrm{T}_{8}-10-14$ dni po $\mathrm{T}_{2}$

$\mathrm{T}_{1}-24$ hours before herbicide (1 leaf of carrot); $\mathrm{T}_{2}-1$ leaf of carrot; $\mathrm{T}_{3}-24$ hours after herbicide (1 leaf of carrot); $\mathrm{T}_{4}-24$ hours before herbicide (2-3 leafs of carrot); $\mathrm{T}_{5}-2-3$ leafs of carrot; $\mathrm{T}_{6}-24$ hours after herbicide (2-3 leafs of carrot); $\mathrm{T}_{7}-24$ hours before herbicide $\left(10-14\right.$ days after $\left.\mathrm{T}_{2}\right) ; \mathrm{T}_{8}-$ $10-14$ after $\mathrm{T}_{2}$

'ocena po 10-14 dniach od ostatniego zabiegu - evaluation 10-14 days after last treatment

${ }^{2}$ wartości oznaczone tą samą literą nie różnią się istotnie przy poziomie $\mathrm{p}=0,05$ - values followed by the same letter are not significantly different at $\mathrm{p}=0.05$

sposobu stosowania. Żółtlica drobnokwiatowa była bardzo silnie niszczona przez metrybuzynę we wszystkich obiektach, natomiast po dodaniu adiuwanta do linuronu zanotowano słabsze zniszczenie tego gatunku.

Silna redukcja liczby i masy chwastów przez metrybuzynę (rys. 2, 3) jest efektem wysokiej skuteczności działania tego herbicydu. Najmniejszą liczbę chwastów stwierdzono po użyciu metrybuzyny $\mathrm{w}$ mieszaninie $\mathrm{z}$ adiuwantem Protector oraz po użyciu tego adiuwanta jeden dzień przed opryskiwaniem herbicydem. Linuron, stosowany $\mathrm{w}$ dawkach dzielonych, redukował liczbę chwastów o $66 \%$, w porównaniu do kontroli, znacznie słabiej niż metrybuzyna. Dodatek biostymulatorów do linuronu, powodował zmniejszenie liczby i masy chwastów, jednak wartości te były i tak wyższe niż po zastosowaniu metrybuzyny. Skuteczność działania metrybuzyny w przeprowadzonych badaniach była podobna, jak w doświadczeniach Anyszki i wsp. (2011), którzy podają że substancja ta stosowana metodą dawek dzielonych ograniczała liczbę chwastów o ponad $96 \%$.

Po zastosowaniu metrybuzyny i linuronu obserwowano nieznaczne objawy fitotoksyczności na roślinach marchwi, dochodzące do $0,5 \%$ (tab. 2). Były to krótkotrwałe objawy w postaci spowolnienia wzrostu oraz miejscowych przebarwień, głównie na dolnych liściach i zanikały po 22-35 dniach od ostatniego zabiegu. Na niewielkie objawy fitotoksyczności na roślinach marchwi, we wczesnych fazach rozwojowych, po zastosowaniu metrybuzyny metodą dawek dzielonych i mikrodawek wskazują Anyszka i wsp. (2011). Zastosowanie biostymulatorów i adiuwantów nie wpływało na selektywność herbicydów dla marchwi, nie obserwowano silniejszych zmian na roślinach czy różnic we wzroście marchwi. Dobrzański i wsp. (2008 b) również nie wykazywali zwiększenia negatywnych objawów na marchwi, po wykonaniu zabiegu łączonego biostymulatorem Asahi SL z linuronem. 
W czasie wegetacji liczba roślin marchwi była wyższa niż przed zbiorem. Największą obsadę w obu terminach oceny zanotowano na poletkach, gdzie zastosowano adiuwant Protector jeden dzień przed metrybuzyną. $Z$ tego obiektu otrzymano też największą masę naci marchwi. Użycie biostymulatorów $\mathrm{z}$ linuronem także korzystnie wpłynęło na zwiększenie masy naci marchwi, w porównaniu do zastosowania samego herbicydu.

Po użyciu adiuwanta Protector jeden dzień przed zastosowaniem metrybuzyny i linuronu, a także mieszaniny metrybuzyny ze stymulatorem wzrostu Asahi SL, zaznaczyła się tendencja wzrostu plonów marchwi (tab. 2). Zwiększenie plonów pod wpływem zastosowania stymulatora Asahi SL otrzymano także w uprawach buraka cukrowego, rzepaku ozimego i pszenicy jarej (Matysiak i wsp. 2011). Najniższe plony korzeni marchwi otrzymano po zastosowaniu metrybuzyny $\mathrm{w}$ mieszaninie $\mathrm{z}$ biostymulatorem AlfaMax i po opryskiwaniu tym biostymulatorem jeden dzień przed użyciem herbicydu, jednak różnice w plonach były statystycznie nieistotne. Na brak wpływu biostymulatora zawierającego wyciagi $\mathrm{z}$ alg morskich na plon marchwi w uprawie ekologicznej, mimo pozytywnego wpływu środka na wzrost wegetatywny roślin, wskazali Gubarewicz i Dobromilska (2010). Wpływ na wzrost wegetatywny różnych preparatów $\mathrm{z}$ glonów morskich obserwowano też $\mathrm{w}$ uprawie pomidora pod osłonami. Następowało przedłużenie gron owocowych oraz zwiększenie plonu ogółem, a nasilenie tych zmian zależało od użytego preparatu oraz odmiany pomidora (Dobromilska i wsp. 2009). Wyniki badań wskazują, że biostymulatory mogą łagodzić stres roślin, związany ze stosowaniem herbicydów, a także zwiększać skuteczność działania herbicydów.

\section{Wnioski / Conclusions}

1. W doświadczeniach $\mathrm{w}$ uprawie marchwi stwierdzono lepsze działanie metrybuzyny stosowanej metoda dawek dzielonych, w porównaniu do linuronu.

2. Asahi SL, AlfaMax i Protector stosowane łącznie lub rozdzielnie z metrybuzyną nie wpływały na jej skuteczność.

3. Dodatek adiuwantów Protector i Olbras 88 EC powodował wzrost skuteczności działania linuronu.

4. Biostymulatory i adiuwanty stosowane łącznie lub rozdzielnie nie powodowały wzrostu fitotoksyczności herbicydów dla rośliny uprawnej.

5. Plony marchwi traktowanej metrybuzyna metodą dawek dzielonych były wyższe niż po zastosowaniu linuronu, jednak różnice nie były statystycznie istotne.

6. Najwyższe plony korzeni marchwi uzyskano stosując biostymulator Asahi SL łącznie z metrybuzyną lub jeden dzień po zabiegu herbicydem oraz po użyciu adiuwanta Protector jeden dzień przed zabiegiem metrybuzyną.

\section{Literatura / References}

Anyszka Z. 2007. Ocena możliwości stosowania linuronu i metrybuzyny z niektórymi graminicydami w uprawie marchwi. s. 29-30. W: Ogólnopolska Naukowa Konferencja Warzywnicza nt. „Postęp w technologii uprawy warzyw korzeniowych”. Skierniewice, $15.11 .2007,64 \mathrm{ss}$

Anyszka Z., Dobrzański A. 1998. Influence of reduced rates and split application of herbicides on weed control and on yield in carrots (Daucus carota L.). Veg. Crops Res. Bull. 49: 49-61.

Anyszka Z., Dobrzański A. 2003. Ochrona marchwi przed chwastami w oparciu o metrybuzynę i pendimetalinę. [Weed control management in carrot with metribuzin and pendimethalin]. Prog. Plant Prot./Post. Ochr. Roślin 43 (2): 513-516.

Anyszka Z., Dobrzański A., Pałczyński J. 2001. New possibilities of split application of herbicides in carrot. Veg. Crops Res. Bull. 54 (1): $117-123$.

Anyszka Z., Korzeniowski M., Kohut M., Golian J. 2011. Efektywność odchwaszczania marchwi metrybuzyną stosowaną metodą mikrodawek. [Effectiveness of weed control by using metribuzin applied with micro-rates method]. Prog. Plant Prot./Post. Ochr. Roślin 51 (3): 1340-1344.

Bellinder R.R., Kirkwyland J.J., Wallace R.W. 1997. Carrot (Daucus carota) and weed response to linuron and metribuzin applied at different crop stages. Weed Technol. 2: 235-240.

Czeczko R., Mikos-Bielak M. 2004. Efekty stosowania biostymulatora Asahi w uprawie różnych gatunków warzyw. Ann. UMCS, Sec. E, 59 (3): 1073-1079.

Dobromilska R., Gubarewicz K., Konieczny M. 2009. Wpływ preparatów z glonów morskich na plon i jakość pomidora uprawianego pod osłonami. Zesz. Probl. Post. Nauk Rol. 539: 143-149.

Dobrzański A., Anyszka Z., Elkner K. 2008a. Reakcja marchwi na ekstrakty pochodzenia naturalnego z alg z rodzaju Sargassum AlgaminoPlant i z leonardytu - HumiPlant. J. Res. Appl. Agric. Engin. 53 (3): 53-58.

Dobrzański A., Anyszka Z., Pałczyński J. 2008b. Response of onion and carrot to Asahi SL biostimulator used with herbicides. p. 7-20. In: "Biostimulators in Modern Agriculture - Vegetable Crops" (Z.T. Dąbrowski, ed.). Plantpress, Warsaw, 81 pp.

Dobrzański A., Pałczyński J., Anyszka Z. 1995. Wpływ niektórych adiuwantów na skuteczność herbicydów w uprawie warzyw. Materiały 35. Sesji Nauk. Inst. Ochr. Roślin, cz. 1: 73-79.

Gawrońska H., Przybysz A. 2011. Biostymulatory: mechanizmy działania i przykłady zastosowań. s. 7-13. W: Targi Sadownictwa i Warzywnictwa - Mat. Konferencyjne. Warszawa, 5-6.01.2011, 68 ss.

Gawrońska H., Przybysz A., Szalacha E., Słowiński A. 2008. Physiological and molecular mode of action of Asahi SL biostimulator under optimal and stress conditions. p. 54-76. In: "Biostimulators in Modern Agriculture - General Aspects" (H. Gawrońska, ed.). Wieś Jutra, Warsaw, 118 pp. 
Gubarewicz K., Dobromilska R. 2010. Wpływ preparatu Bio-algeen S-90 na wzrost i plonowanie marchwi w uprawie ekologicznej. s. 78-79. W: Ogólnopolska Konferencja Naukowa „Proekologiczna uprawa warzyw - problemy i perspektywy”. Siedlce, 24-25.06.2010, 192 ss.

Maciejewski T., Szukała J., Jarosz A. 2007. Wpływ biostymulatora Asahi SL i Atonik SL na cechy jakościowe bulw ziemniaków. J. Res. Appl. Agric. Engin. 52 (3): 109-112.

Matysiak K., Adamczewski K. 2009. Regulatory wzrostu i rozwoju roślin - kierunki badań w Polsce i na świecie. [Plant growth regulators application - studies in Poland and in the world]. Prog. Plant Prot./Post. Ochr. Roślin 49 (4): 1810-1816.

Matysiak K., Adamczewski K., Kaczmarek S. 2011. Wpływ biostymulatora Asahi SL na plonowanie i wybrane cechy ilościowe i jakościowe niektórych roślin rolniczych uprawianych w warunkach Wielkopolski. [Response of some crops cultivated in Great Poland to application of Asahi SL]. Prog. Plant Prot./Post. Ochr. Roślin 51 (4): 1849-1857.

Praczyk T., Adamczewski K. 1996. Znaczenie adiuwantów w chemicznej ochronie roślin. [The importance of adjuvants in chemical crop protection]. Prog. Plant Prot./Post. Ochr. Roślin 36 (1): 117-121.

Szweykowska A. 1997. Fizjologia roślin. Wyd. Naukowe UAM, Poznań, 250 ss.

Woźnica Z. 2003. Współdziałanie adiuwantów a skuteczność chwastobójcza herbicydów. [Adjuvant interaction and efficacy of herbicides]. Prog. Plant Prot./Post. Ochr. Roślin 43 (1): 473-479.

Woźnica Z., Adamczewski K. 2005. Adiuwanty do środków ochrony roślin - aktualne trendy badawcze. [Adjuvants for agrochemicals current research trends]. Prog. Plant Prot./Post. Ochr. Roślin 45 (1): 524-532. 